\title{
Perder el miedo, romper el mito. Reflexión mediática y representación del Partido Comunista entre el Franquismo y la Transición ${ }^{\star}$
}

\author{
José Carlos Rueda Laffond \\ Universidad Complutense de Madrid
}

RESUMEN: Este trabajo se aproxima al uso de los medios de comunicación, y a la presencia en los mismos, del Partido Comunista de España (PCE) entre el tardofranquismo y la transición democrática. El artículo se interesa por la relación establecida entre política, discursos de identidad y prácticas de representación. Para ello propone una interpretación fundamentada en fuentes escritas y audiovisuales desde el enfoque del análisis cualitativo. El texto aborda, más especificamente, algunas claves presentes en la reflexión comunista sobre Televisión Española (TVE). Durante la dictadura la televisión fue valorada como una herramienta de control sociocultural e intervención política. Sin embargo, el PCE animó la movilización laboral en aquel medio. A su vez, desde 1976 las necesidades de reforzar la visibilidad pública del partido favorecieron la revisión de sus directrices propagandísticas y sus instrumentos de socialización, al tiempo que se intentó articular una renovada escenificación pública como organización de masas.

\section{Palabras Clave: Partido Comunista de España; Franquismo; Tran- sición Democrática; Propaganda; Televisión; Re- presentación Audiovisual.}

* Trabajo resultado de los Proyectos «Televisión y memoria. Estrategias de representación de la Guerra Civil y la Transición» (ref. HAR2010-20005, MICINN), «Memorias de segundo grado: posmemoria de la Guerra Civil, el Franquismo y la Transición Democrática en la España contemporánea» (ref. CSO2013-41594-P, MINECO) y «Memorias en segundo grado. Posmemoria de la Guerra Civil y el franquismo en la España del siglo XXI» (2013 LINE-01, Universitat Rovira i Virgili-Banco Santander). Se han consultado los siguientes centros documentales: Archivo Histórico del Partido Comunista de España (AHPCE); Fundación Francisco Largo Caballero, Fondo José Antonio Alzola Martínez de la Luna (FFLC); Fundación Primero de Mayo, Archivo de Historia del Trabajo (AHT) y Centro de Documentación de Radiotelevisión Española. 


\section{Lose the Fear, Break the Myth. Media Reflection and Representation of Communist Party between Francoism and Democratic Transition}

ABSTRACT: This work analyzes the use and presence in the media of the Communist Party of Spain (PCE), between Francoism and Democratic Transition. The paper focuses on the relationship established between policy, discourses about identity and memory and practices of representation. Its interpretation is bases on written and visual sources, from the approach of qualitative content analysis. The text approaches, more specifically, the keys present in communist reflections on Spanish Television (TVE). During the dictatorship TVE was assessed as social, cultural and political tool of control. However, the PCE also encouraged labor mobilization in this service. Since 1976, need to strengthen public visibility of PCE favored reviewing of its propaganda and instruments of socialization, while attempted to articulate a renewed public representation as a mass organization.

KEY WORDS: Spanish Communist Party; Francoism; Democratic Transition; Propaganda; Television; Audiovisual Representations.

\section{OBJETO DE ESTUDIO Y FUNDAMENTACIÓN METODOLÓGICA}

Este texto estudia distintas formas de interpretación y presencia del Partido Comunista de España (PCE) entre el tardofranquismo y el inicio de la transición ${ }^{1}$. Pretende analizar cómo los comunistas valoraron diferentes medios de comunicación, $\mathrm{y}$, paralelamente, cómo desde varios medios se representó y apreció al colectivo comunista. Desde ahí se derivará hacia asuntos más generales, tratando aspectos de política partidaria, estrategias propagandísticas $\mathrm{u}$ orientaciones presentes en campañas de movilización.

Los objetivos del artículo pueden agruparse en una triple perspectiva. Se pretende abordar la visión crítica que, desde los parámetros de una cultura relativamente institucionalizada como fue la comunista española, se llevó a cabo sobre cuestiones como la comunicación de masas, las relaciones entre poder y esfera pública, o la incidencia de las industrias culturales. En segundo lugar, se considerarán algunas necesidades de uso de los medios por parte del PCE, en lógica con las pretensiones coyunturales de presencia pública manejadas por esta organización. Finalmente, el texto quiere explorar distintas formas históricas de relación establecidas entre los medios audiovisuales y el

${ }^{1}$ Como estudios esenciales, BUENO, GARCÍA E HINOJOSA, 2007, 2: 13-425. MOLINERO E YSÀS, 20 (Madrid, 2008): 21-42. MOLINERO E YSÀS, 2010. TREGLIA, 2012. ANDRADE, 2012. 
partido. En este sentido, se afrontarán cuestiones como sus formas de presencia y representación en cine o televisión ${ }^{2}$.

El trabajo pivota, pues, en torno a las mecánicas de construcción, gestión o circulación de discursos desde el entramado mediático, y a su implicación con determinados agentes políticos. Se desea estudiar la estrategia mediática comunista en correspondencia con varios niveles de socialización (interno y proyectado hacia la esfera pública). Dicha mecánica puede vincularse también con las lógicas de articulación y reproducción de un posible «sistema de ideas $»^{3}$. Ello permite valorar al PCE como comunidad identitaria articulada por pautas específicas, así como por valores transversales derivados de referentes externos a la propia organización.

La idea de entramado mediático se entiende desde una óptica amplia. Consideraremos que no sólo integró un compendio de relatos informativos, sino también narrativas didácticas o de entretenimiento. Además, los medios de comunicación coadyuvaron en la creación y reconocimiento de un universo simbólico asociado al partido, actuaron como instrumentos de cohesión o denuncia, como herramienta en la estrategia cultural, y como «espacios de lucha» contra la dictadura. Semejante diversidad de potencialidades plantea un complejo emplazamiento en las escalas de configuración y transmisión de valores, o ante la red de dispositivos militantes donde tomó forma la (auto) percepción de «lo comunista» (relaciones de proximidad, mecanismos de encuadre, actos y rituales públicos... $)^{4}$.

Desde un punto de vista metodológico y procedimental, la interpretación aquí propuesta se apoya en el análisis cualitativo de un amplio abanico de fuentes. Dicho corpus incluye documentación interna de los órganos de dirección del PCE, propaganda impresa, piezas periodísticas y filmaciones televisivas o cinematográficas (ficciones dramáticas, documentales didácticos, obras conmemorativas, rodajes clandestinos, largometrajes militantes o «spots» electorales).

Los aspectos indicados dibujan unas coordenadas amplias. Examinar las mecánicas de conexión entre el PCE, los medios y la esfera pública escapa a una visión centrada sólo en la «política desde arriba», el enfoque historiográfico tradicional sobre el $\mathrm{PCE}^{5}$. No cabe duda que el estudio de las estrategias de propaganda y socialización deben vincularse con determinados condicio-

2 Sobre tales cuestiones, NISTAL, 2007: 19-39. LÓPEZ HERNÁNDEZ, 25 (2007): 381-396. ZARAGOZA, 2008. PRIETO, 10/2 (2013).

3 DAWISHA (2005): 463-493. TILEAG ̃̃ (2012): 6-7.

4 Véase, por ejemplo, CRUZ, 2001: 187-201, o respecto al Partit Socialista Unificat de Catalunya (PSUC), DOWLING, 43/3 (2013): 495-497.

5 Dicho enfoque, su revisión o «normalización», en ERICE (2002): 315-330. BUENO Y GÁLVEZ, 24 (2005): 335-345. GINARD, 2007: 19-47. DOMÉNECH, 2009: 93-99. 
nantes, como el análisis de las tácticas trazadas por la elite dirigente. Pero, asimismo, puede implicarse con la caracterización de las bases sociales e intelectuales de la organización, o con las singularidades e intersecciones definidas entre el «espacio cultural comunista»y otros marcos relacionales ${ }^{6}$.

\section{DIVERSIFICACIÓN PROPAGANDÍSTICA Y PERCEPCIONES MEDIÁTICAS}

\section{Prácticas audiovisuales antifranquistas}

Durante la dictadura franquista el discurso comunista se canalizó a través de una oferta diversificada de cauces audiovisuales. El más destacado fue Radio España Independiente (Estación Pirenaica), creada en 1941 y que mantuvo sus emisiones hasta 1977. La REI constituyó un caso único de concepción y gestión propagandística no sólo por su larga duración, sino por su relevancia cualitativa. La estación mantuvo una presencia constante en el interior del país, actuando como voz reconocible en la oposición a Franco y como instrumento reactivo frente a la información suministrada o controlada por el régimen. La Pirenaica puede ser tildada de herramienta con pretensiones socializadoras ante la audiencia generalista, si bien su eficacia en este terreno es difícil de medir. Más ajustado resulta aquilatar sus funciones ante la estructura interior del PCE. Suministró una oferta de contenidos vertebrada por la didáctica oficial del partido, sirvió de plataforma para su integración orgánica, y potenció el encuadramiento y lazos entre simpatizantes o futuros militantes, ayudando a conformar la reproducción del colectivo. De esta forma, actuó como mecanismo "contra-informativo» de agitación, movilización y cohesión. Y si bien su grado de influencia parece que decreció desde mediados de los años sesenta - entre otros factores, probablemente como consecuencia del desarrollo de la televisión-, desde la dirigencia siempre se le prodigó un tono entusiástico, estimándosela como factor esencial para asegurar la presencia pública del partido ${ }^{7}$.

Otro ámbito de influencia del PCE fue el cine, si bien aquí deben apuntarse orientaciones y estrategias más plurales, producidas tanto fuera como dentro de España. No contamos con un trabajo de conjunto que estudie la conexión

${ }^{6}$ BUENO Y GÁLVEZ, 2007 y 2009. Sobre la militancia en la transición, GARRIDO Y GONZÁLEZ, 6 (2008): 71-87. BARRANQUERO, 19/1 (2012): 103-140. La categoría de «espacio cultural comunista», en URÍA, 1996: 249-311.

7 ZARAGOZA, 2008: 151-213 y 395-399. Perspectivas del movimiento estudiantil, AHPCE, 51.2, 1970. Sobre las últimas estrategias de movilización promovidas desde la emisora véase, por ejemplo, Dolores Ibárruri se dirige a las mujeres españolas, AHPCE, Dirigentes, 22.1, 2 de octubre de 1975 . 
entre las prácticas cinematográficas y el partido, aunque sí se han abordado aspectos monográficos ${ }^{8}$. El discurso comunista se expresó desde una diversidad de narrativas. Por ejemplo, el documental Mourir à Madrid (1962, con realización de Frédéric Rossif y guión de Madeleine Chapsal) fue una obra orgánicamente desvinculada del PCE. No obstante, interiorizaba muchas claves sobre la Guerra Civil manejadas por la publicística del partido, como el carácter reaccionario de la sublevación o las categorías interpretativas de «guerra nacional-revolucionaria» y «República de nuevo tipo». El eco internacional logrado por Mourir à Madrid llegó a provocar dos filmes de contrapropaganda directa franquista: Morir en España (Mariano Ozores, 1965) y ¿Por qué morir en Madrid? (Eduardo Manzanos, 1966). Especialmente el primero de ellos sirvió de soporte para actualizar muchos de los leitmotiv anticomunistas clásicos del régimen, como la influencia soviética, el «oro de Moscú» o los fusilamientos en Paracuellos.

El imaginario comunista se inscribió, además, en otras pautas de codificación. Con una implicación variable de valores como reconciliación o memoria traumática cabe citar La guerre est finie (Alain Resnais, 1966), una ficción con guión autobiográfico de Jorge Semprún, recién expulsado del PCE. Otras obras realizadas en España abarcaron desde un enfoque pseudoficial franquista - Suspensos en comunismo (Eduardo Manzanos, 1956), El camino de la Paz (Rafael G. Garzón, 1959)—, a metáforas relativamente próximas a los postulados del PCE, como La venganza (Juan Antonio Bardem, 1957), España otra vez (Jaime Camino, 1968) o Lejos de los árboles (Jacinto Esteva y producción de Pere Portabella, 1963-1970). Cabe vincular algunos de esos trabajos con las mecánicas de cohesión o proselitismo del PCE. La más significativa fue la «Organización de Cineastas», creada a inicios de los cincuenta, y que actuó como instrumento de captación y caja de resonancia del partido. Se expresó a través de distintas publicaciones (Objetivo, Nuestro Cine, Cinema Universitario...), o gracias a la presencia de militantes y simpatizantes comunistas en la productora UNINCI ${ }^{9}$. En todas estas iniciativas el impulso de Ricardo Muñoz Suay y Juan Antonio Bardem resultó decisivo ${ }^{10}$.

A finales de los años sesenta cristalizó otra modalidad de enunciación: el «cine militante». En él se incluyeron obras de compromiso sociopolítico habitualmente resueltas mediante la representación documental ${ }^{11}$. Pero esa etiqueta de «militante» resulta imprecisa. Sus expresiones formales o temáticas fueron plurales, abarcando influencias derivadas del «nuevo cine» español, el «cinéma verité» y el «free cinema», la experimentación y el «underground»,

\footnotetext{
8 DÍEZ PUERTAS, 2001: 63-169. PRIETO, 2012.

9 SALVADOR, 2006.

10 CERÓN, 2004: 29-37.

11 ARNAU, 2006.
} 
el cine político, o la reflexión sobre montaje, objetividad y dramaturgia formulada en la URSS en los años veinte. Su alcance superó, además, el estricto campo creativo o propagandístico. Muchas iniciativas desembocaron en fórmulas cooperativistas que discutían el rol del director - autor, los estándares de producción comercial o, incluso, el propio encuadramiento en partidos de izquierda ${ }^{12}$. En este sentido, las relaciones entre cine militante y PCE fueron de intensa implicación, pero no faltaron tensiones estéticas, políticas o personales que evidenciaron la incapacidad del partido para canalizar este movimiento, por otro lado heterogéneo.

Por ejemplo, algunos realizadores acabaron distanciándose y formulando un cine radical alternativo tanto frente a las fórmulas de esparcimiento comercial como al realismo social. Un caso notable fue el de Helena Lumbreras, promotora a inicios de los setenta del $"$ Colectivo de Cine de Clase» ${ }^{13}$. Formada en el Centro Sperimentale de Cinematografía, realizó Espagna 68 (El hoy es malo, pero el mañana es mío) (1968), un documental financiado por Unitelefilm, la productora del Partido Comunista Italiano (PCI). En él se aproximaba a distintos colectivos de oposición al franquismo (trabajadores, estudiantes, mujeres....). En 1971 Lumbreras y su compañero Mariano Lisa fueron expulsados del PSUC. Meses antes, junto a Llorenç Soler, había realizado El cuarto poder, una reflexión sobre la prensa generalista española, los mecanismos de censura o autocensura y las iniciativas de contra-información clandestina, todo ello desde un prisma que cabría situar en los límites del discurso oficial comunista.

Otros colectivos cinematográficos mantuvieron una vinculación más estrecha con el espacio cultural o político del PCE o el PSUC. Fue el caso de la "Comisión de Cine de Barcelona» (CCB, 1970) responsable de París, 20 de juny de 1971 (míting a Montreuil), que recogía un acto encabezado por Dolores Ibárruri y Santiago Carrillo. El documental se realizó de forma colectiva e independiente, aunque el PCE se comprometió a amortizarlo abonando «un pequeño sobrecoste», reservándose algunas copias para su exhibición en España o en círculos de exiliados y emigrantes, mientras que la CCB lo comercializó en circuitos internacionales. Un remontaje de París, 20 de juny... se vendió y emitió en la televisión sueca. Su mecánica de producción y distribución abrigó esperanzas en círculos comunistas con vistas a componer un posible esquema de manufactura en serie basado en rodajes en 16 milímetros, tirada inicial de pocas copias y distribución entre «productores demócratas, (...) amigos del partido». O ya en el exterior, aprovechando las redes comunistas en Francia e Italia y el interés de televisiones como la ORTF, la BBC,

12 Cfr. con el debate «Cine militante», El Viejo Topo, IV/1977: 55-59.

13 CAMÍ-VELA, 2009: 207-223. 
la RAI o las cadenas escandinavas, por materiales audiovisuales alternativos a los producidos por el ministerio de Información y Turismo ${ }^{14}$.

\section{¿Un arma del diablo?}

Televisión Española (TVE) ofrecía notables diferencias frente a esas otras emisoras públicas europeas. En este caso debe hablarse de un servicio ofertado en régimen de monopolio, vinculado con el aparato político y burocrático de la dictadura. El consumo televisivo fue en progresivo aumento en España durante el decenio de los sesenta según se solidificaba y multiplicaba su base de financiación, la publicidad privada. Sobre esa base se acoplaron los planos - aparentemente contradictorios - de un rígido control gubernativo junto a una programación fundamentada en el esparcimiento, la difusión de pautas consuntivas masivas y la proyección de valores que reflejaban actitudes o formas de comportamiento cada vez más abiertas y dinámicas ${ }^{15}$. A estas dimensiones debe añadirse el valor otorgado a la televisión desde la retórica desarrollista, que la percibió como palanca de modernidad y difusión de una «cultura popular» susceptible de amplificar la aceptación del régimen ${ }^{16}$.

TVE fue una televisión oficialmente anticomunista que reiteró las claves habituales del discurso legitimador oficial franquista ${ }^{17}$. A pesar de ello, sus contenidos no deben apreciarse como un todo compacto. Por ejemplo, en el verano y otoño de 1975, en vísperas de la muerte de Franco, se programó la serie documental Tiempos de España, que glosaba la trayectoria de la II República como plano inexorablemente inclinado al caos, en lógica con el enfoque historiográfico planteado desde 1965 por la Sección de Estudios sobre la Guerra de España. Sin embargo, en noviembre de aquel año TVE también colaboró en la realización - aunque no lo emitió - de un informativo especial de la ORTF titulado España con y sin Franco, donde participaron personalidades tan dispares como Gonzalo Fernández de la Mora, Miguel Boyer, Federica Montseny o Federico Melchor. El reportaje «Muerte de Franco», emitido el 25 de noviembre en el espacio Informe Semanal, se caracterizó, por su parte, por un estilo ideológicamente aséptico y denotativo, muy distante del tono hagiográfico que dominó la programación oficial dedicada a Franco con motivo de su fallecimiento.

14 Primera conferencia de profesores comunistas en las universidades españolas, AHPCE, Fuerzas de la Cultura, 331-334, 6 de junio de 1973, pp. 5-9. Integraron la CCB, entre otros, Pere Portabella, Carles Duran, Manuel Esteban o Pere Fagés. Sobre las filmaciones alternativas a las oficiales franquistas, FUERTES: 2013.

${ }^{15}$ Cfr. con GUTIÉRREZ LOZANO, 2006: 299-399.

16 RUEDA Y CHICHARRO, 2006: 98-136.

17 HERNÁNDEZ CORCHETE, 2012: 26-39. 
En todo caso, las valoraciones comunistas sobre TVE siempre estuvieron dominadas por una percepción crítica. Tales valoraciones se expresaron tanto en «lecturas desde abajo», como en interpretaciones formuladas desde el «frente cultural» del partido ${ }^{18}$. En ambos casos no faltaron enjuiciamientos enraizados con la tradición de la Escuela de Frankfurt. Esta óptica se evidenció, por ejemplo, en las frecuentes denuncias sobre «grupos monopolistas» interesados en evitar «que otros sectores (sociales pudiesen) ser informados». $\mathrm{O}$ a través de apreciaciones vertidas en fanzines comunistas, que tildaban a TVE de instrumento «al servicio de la escandalosa propaganda capitalista» y de un consumismo alimentado gracias a la publicidad comercial ${ }^{19}$.

Una forma de «lectura desde abajo» fueron las cartas con opiniones de oyentes remitidas a la Pirenaica en Bucarest durante los años sesenta. En ellas se comentaban espacios - como Telediario, Buenas noticias o Rueda de prensa - desde ese prisma de explícita denuncia antifranquista. La pequeña pantalla era percibida como herramienta de propaganda incesantemente orientada a difundir una visión positiva del régimen entre las capas populares. Sin embargo, también se creía que esa pretensión manipuladora podía desvelarse si se estaba atento a algunos detalles. Coincidiendo con la retransmisión de los fastos de los XXV Años de Paz, en mayo de 1964, un telespectador percibió que «en el desfile de la Victoria (...), la TV no pudo dar planos de masas por la ausencia de espectadores»; o como, en el cierre de otra emisión, las cámaras mostraron «el momento que la mano derecha de Franco (el brazo caído y pegado al cuerpo) se agitaba convulsivamente contra el muslo». El contraste entre triste realidad del franquismo y espejismo televisivo, «colmo del jesuitismo y la hipocresía», alcanzaba grado de «mentira de enormes proporciones» según otro televidente anónimo («el Lenin de Valencia»), cada vez que se narraban los hipotéticos logros de la dictadura en materias como los derechos sindicales o la política de vivienda. Pero las cartas a la Pirenaica no manifestaron sólo enunciaciones de rechazo, también lo hicieron en términos de resistencia e identidad inclusiva. Junto a la denuncia de la dimensión espuria del discurso televisivo - «cuatro tonterías, cuentos infantiles»-, muchas cartas afirmaron valores como el «patriotismo» o el orgullo de pertenecer a la clase trabajadora ${ }^{20}$.

La conexión entre televisión y dictadura también fue evaluada en otros círculos comunistas estimando su eficacia proselitista. Según la interpretación de profesionales del audiovisual, TVE constituía un «monopolio cultural informativo (...) formidable», y algunas maniobras habían resultado especial-

18 Cfr. con PALA, 2010.

19 La importancia..., AHPCE. «Las diversiones», Adelante, s.f. (1971): 3. «La publicidad», Topo Obrero, VII/1973: 3-5.

20 AHPCE, Correo de la Pirenaica, 191a, 9 y 191b, 12 y 16. 
mente útiles para el régimen, como el llamamiento de Franco al voto en el referéndum de 1966 o «la campaña publicitaria (de) Juan Carlos, que culminó con la retransmisión en directo» de su proclamación como sucesor, en julio de 1969. Tales apreciaciones pueden relacionarse - en términos de consideración sobre calidad y alcance del medio - con la atención dedicada a algunas declaraciones televisivas de prohombres del régimen, que fueron analizadas con sumo interés por los dirigentes comunistas ${ }^{21}$.

La conmemoración del décimo aniversario del inicio de las emisiones de TVE propició, a su vez, críticas periodísticas que insistieron en ese impacto manipulador y «mutilador» sobre la opinión, al tiempo que subrayaban el tono «adormecedor» y «calmante de las iras populares» generado por la oferta de entretenimiento. Esta última consideración fue ganando terreno desde finales de los años sesenta, según se afianzaba el consumo televisivo entre los estratos populares urbanos. La proliferación de receptores en el espacio doméstico, la generación de audiencias millonarias, el surgimiento de un «star - system» propio de la pequeña pantalla, junto a la censura y fiscalización informativa, reforzaron la visión de un medio progresivamente trastocado en «opio del pueblo» y en «embrutecedor desligado de la realidad ciudadana» ${ }^{22}$.

Tales consideraciones sintetizaban, empero, un aparato crítico más depurado que, en forma de reprobación sociocultural de la televisión, se fue definiendo durante la recta final del franquismo. Tuvo presencia puntual en la prensa del partido, aunque incidió en un argumentario que se proyectó más allá del espacio cultural comunista y del tiempo histórico del franquismo, influyendo en otras lecturas negativas posteriores, realizadas durante la transición o en la primera historiografía sobre el medio ${ }^{23}$. El análisis formalizado a finales de los años sesenta e inicios de los setenta se basaba en la lógica de que una forma de rechazar a Franco era rechazando su televisión, y se fundaba en la naturaleza de TVE como instrumento domesticador. Según esta visión, el medio constataría y reproduciría un esquema de valores cimentados en la represión ideológica y el control social, actuando como herramienta especializada en suministrar bienes culturales banales.

Dos ensayistas sirven de paradigma para dicho enfoque: José María Rodríguez Méndez y Manuel Vázquez Montalbán. Ambos encarnaron un perfil progresista ligado al mundo del periodismo y la literatura y, desde ahí, manejaron ópticas paralelas sobre la naturaleza de TVE. Pero también copar-

${ }^{21}$ Primera conferencia..., AHPCE, p. 12. La declaración de Arias Navarro en la TV, AHPCE, Nacionalidades y Regiones (Madrid), 745, marzo de 1975.

${ }^{22}$ «Notas sobre la Televisión Española», Libertad para España, 2a quincena XII/1966: 8. «Televisión Española. Entre la censura y la represión», Información Española, $2^{\mathrm{a}}$ quincena I/1973: 26-28.

${ }^{23}$ PALACIO, 2005: 80-81 y 86. 
ticiparon en lo que cabría entender como el «deber ser» de la «intelligentsia» y su necesidad de posicionarse ante ciertas contradicciones - las fricciones entre conocimiento formativo y mercantilismo, o entre imperialismo cultural e idiosincrasia nacional-, algo que la televisión tendía a exasperar.

Rodríguez Méndez fue un crítico pionero. Sus comentarios aparecieron desde inicios de los años sesenta en el periódico El Noticiero Universal. En 1971 y 1973 publicó dos breves ensayos dedicados a estudiar la «tentacular, gigantesca y aplastante televisión», en editoriales vinculadas con la izquierda (Laia y Ediciones 99 ${ }^{24}$. Un avance de dicha perspectiva había aparecido años antes en otro soporte del espacio cultural comunista: la revista Realidad ${ }^{25}$. En aquel artículo Rodríguez Méndez tipificaba las estrategias dirigistas en TVE, en el contexto posterior al referéndum de 1966, como resultantes del «interés privado de clan» de las familias políticas franquistas. Desde esa premisa, abordaba las dinámicas de captación y fidelización del telespectador popular: la agresividad ideológica, los silencios y prohibiciones, la inculcación doctrinaria o moralista, la fiscalización de la opinión pública y la labor masificadora. Tal compendio de usos permitía diagnosticar el carácter alienador de la penetración televisiva. No obstante, Rodríguez Méndez también llamaba la atención sobre la necesidad de proceder a su crítica sistemática, ya que no bastaba con el mero despego frente a «esa caja de idioteces». El «elegante desprecio de los intelectuales (suponía abandonar) un campo de lucha muy concreto», necesario para construir un proyecto cultural y formativo democrático y crítico. Esta perspectiva resultaba afín con lo reivindicado en otros países por algunos intelectuales o profesionales interesados en la didáctica televisiva, como Roberto Rossellini.

La reflexión periodística progresista española llegó a reunir puntualmente distintas sensibilidades ideológicas en un ejercicio de crítica compartida a la televisión. En 1972 Cuadernos para el Diálogo publicó un monográfico donde se analizaban las diferentes facetas del medio: los condicionantes socioculturales del entretenimiento, sus particularidades de gestión frente a otros «modelos democrático-pluralistas», su impacto desmovilizador o la excepcionalidad de su fórmula de financiación privada ${ }^{26}$. Este monográfico puede advertirse como muestra de la creciente atención que despertaba la televisión

24 RODRÍGUEZ MÉNDEZ, 1973 y 1971: 8.

25 «Televisión Española, un servicio estatal», Realidad. Revista de cultura y política, VII/1967: 119-125.

26 LÓPEZ GUERRA, Luis, «TV y conflictos sociales», Cuadernos para el Diálogo, VII1972: 168. En este número participaron José María Rodríguez Méndez, Vicente Verdú, Manuel Jiménez de Parga o Cristina Almeida. 
no sólo como instrumento político encuadrado en las estructuras de poder estatal, sino esencialmente como articulador activo de la cultura popular ${ }^{27}$.

Ambos aspectos compusieron la columna vertebral para otro texto básico para la crítica comunista: El libro gris de Televisión Española (1973), de Manuel Vázquez Montalbán. Este ensayo partía de una explícita declaración analítica, interesada por abordar la explotación económica, la instrumentalización política y la rentabilidad sociocultural de la televisión ${ }^{28}$. El libro formalizaba, en este sentido, un estándar valorativo enraizado con las percepciones antes comentadas. Recalcó el maridaje entre control informativo y viabilidad comercial publicitaria. Ambos vectores componían la trama para una televisión esencialmente ligada a la lógica del capitalismo monopolista de Estado, un aspecto básico en la reflexión del PCE en vísperas de la transición. Pero El libro gris... desarrollaba un molde interpretativo de mayor calado. Su enfoque sobre el papel de TVE en la cosmovisión franquista de la paz, el orden o el bienestar material era compatible con otros textos contemporáneos derivados de la Escuela de Frankfurt o desde los nacientes Estudios Culturales. En ellos, y a partir de la relectura de nociones como «efecto ideológico» de Gramsci o «aparatos ideológicos de Estado» de Althusser, se apreciaba a la televisión como herramienta que institucionalizaba visiones de la realidad o socializaba aquiescencias y sometimientos sociales sin coacción aparente desde el poder ${ }^{29}$.

\section{RESISTENCIAS Y REPRESENTACIONES ENTRE LA DICTADURA Y LA TRANSICIÓN}

\section{Los medios como ámbitos de conflicto y afirmación}

En abril de 1971 Mundo Obrero informaba del estallido de «la primera huelga en la Televisión». Como consecuencia, agentes de la Brigada PolíticoSocial ocuparon sus instalaciones ${ }^{30}$. Dicho suceso permite apreciar otra perspectiva sobre TVE. Más allá de la magnificación de aquel hecho en la prensa comunista, éste evidenció las consecuencias derivadas del «gigantismo»e incremento de trabajadores. La situación de los «colaboradores» (profesionales sin relación ni derechos contractuales, pero sometidos a unas exigencias equiparables o superiores a las del personal en plantilla), las deficiencias en el régimen laboral establecido en el Reglamento de 1959, la discrecionalidad en

27 CERDÁN, 2005: 232-234.

28 VÁZQUEZ MONTALBÁN, 1973.

29 Cfr. con HALL, 1977: 547-391.

30 «La primera huelga en la Televisión», Mundo Obrero (MO), 17/IV/1971: 5. «Por primera vez, huelga en la Televisión Española», Información Española, IV/1971: 4. 
las plantillas, la ambigua personalidad empresarial dada la sujeción orgánica a Información y Turismo... Todo ello compuso el complejo marco donde debe situarse el surgimiento de un tejido reivindicativo y de movilización vinculado a Comisiones Obreras, conformado básicamente por militantes comunistas ${ }^{31}$.

La huelga de 1971 evidenció el sesgo de la televisión como espacio de conflicto laboral, resistencia ideológica y disenso político. Cabe situar en torno a 1969 los primeros brotes de estas «comisiones de trabajadores». Su desarrollo puede reconstruirse al hilo de la prensa clandestina. Este fondo documental permite apreciar reivindicaciones y temores coyunturales del colectivo, sus formas de presión, o sus denuncias frente a abusos o «chivatos $\gg{ }^{32}$. Al tiempo, permite constatar cuál fue la cultura de grupo y sus percepciones sobre la naturaleza, usos y perversiones de la televisión por el franquismo. Frente a su finalidad ideal - TVE como «portavoz objetivo de la información y medio para el enriquecimiento cultural del pueblo»—, se estimaba que se había convertido en escenario para el enfrentamiento entre camarillas del régimen («los gangsters del Opus Dei» frente a «los pistoleros fascistas de la Secretaría General del Movimiento») $)^{33}$. En este sentido, los hechos del 2 de abril de 1971 evidenciaban que se había «perdido el miedo» y se había «roto el mito», al trasladarse la protesta a las entrañas de un organismo gubernamental con este alcance y valor simbólico ${ }^{34}$.

Respecto a su identidad política, el colectivo manejó postulados genéricos procedentes del programa comunista. Reivindicó objetivos como la amnistía y el reconocimiento de las libertades, la ruptura democrática a través de la formación de un gobierno de amplia coalición, o la convocatoria electoral para clarificar la forma del régimen ${ }^{35}$. Esa identidad ideológica permite situar también el carácter de las acciones represivas que desembocaron en la detención y despido de seis trabajadores, en febrero de $1972^{36}$. Dicho suceso puede reconstruirse desde dos puntos de vista. Por un lado, en relación con el interés gubernamental por desarticular a sus responsables e instigadores. Cabe considerar, al respecto, los informes de delación conservados en el Archivo General de la Administración, donde se señalaron motivaciones y nombres propios coincidiendo con este brote de conflictividad ${ }^{37}$. Dichos informes alertaron

31 «Otra cara de TVE», Hora de Madrid, III/1970: 4-5.

32 Información sobre Cine y Televisión (ICT), AHT, II-1970: 1-2. Boletín de Cine, Teatro y Televisión (BCTT), V/1972: 7.

33 ICT, АHT, XII/1969: 2. III/1970: 4.

34 ICT, AHT, IV/1971: 1 y 3.

35 BCTT, AHT, X/1971: 2-3.

36 Los detenidos fueron el realizador Francisco Abad, el redactor y responsable de la agrupación sindical, Ángel de la Cruz, los montadores Carmen Frías y Miguel González Sinde y el operador de vídeo-tape José Luis Gallego.

37 PALACIO, 2012: 55-57. 
sobre la constitución en TVE de una «célula comunista», y exactamente así fue caracterizada en la prensa generalista ${ }^{38}$. Otro punto de vista procede de las declaraciones de los detenidos en 1972 a la dirección del PCE, incorporadas en un informe sobre posibles responsabilidades ${ }^{39}$. En él se reseñaron las condiciones del apresamiento y los interrogatorios, donde además de agentes de la Brigada Político-Social (el comisario Conesa) estuvo presente un funcionario de Información y Turismo.

También desde inicios de los años setenta deben situarse otras estrategias de movilización. Un ejemplo lo encontramos en la Escuela Oficial de Cinematografía, que vivió entre 1967 (Primeras Jornadas Internacionales de Escuelas de Cine, en Sitges) y 1971 (desaparición de la Escuela), un convulso período dominado por las acciones de concienciación democrática y protesta ${ }^{40}$. Otra muestra de oposición, en este caso en forma de «cine militante», estuvo protagonizada por el Colectivo de Cine de Madrid (CCM). Este grupo estuvo integrado por Andrés Linares y Miguel Hermoso desde 1970; y, ya desde 1975 por Linares, Tino Calabuig, Estebán Román, Adolfo Garijo y otros profesionales. Todos ellos fueron militantes comunistas, y sus documentales pueden valorarse como muestras canónicas del imaginario del PCE y de sus objetivos socializadores en aquellos años. A su vez, la actividad del CCM se prolongó durante la transición, lo cual permite ilustrar la evolución y las mutaciones de su discurso.

El colectivo surgió de discusiones internas en círculos de profesionales y estudiantes sobre la necesidad de crear un grupo estable que asumiese «tareas específicas (como) cineastas del partido, (poniendo) capacidades y conocimientos al servicio de la lucha popular». Se trataba de sustanciar una praxis, teorizada desde finales de los años sesenta, en forma de cine analítico y reflexivo, capaz de interaccionar con el entorno conflictivo que pretendía retra$\operatorname{tar}^{41}$. Sus primeros trabajos - los mediometrajes Presos, Universidad 71-72 y Proceso 1001 - se realizaron sin apoyo de la estructura oficial del PCE, aunque sí contaron con el respaldo de algunos militantes, siendo las filmaciones reveladas, montadas y sonorizadas en Roma y París ${ }^{42}$. Con ese material se generó una primera oferta, comercializada a varias televisiones internacionales o exhibida en España de forma clandestina.

Ese sistema artesanal de producción se redefinió en vísperas de la muerte de Franco. Se incrementó el número de personas, se repartieron funciones y se abarataron los costes. Los temas seguían marcados por la actualidad. Pero

38 «Célula comunista en TVE?», $A B C, 11 / \mathrm{II} / 1972: 27$. «Presunta célula comunista en Televisión Española», $A B C, 8 / \mathrm{V} / 1974: 40$.

39 Sobre detención de TVE, AHPCE, Nacionalidades y Regiones (Madrid), 562.

40 TRENZADO, 1999: 198-200.

41 Cfr. con la ponencia de Pio Baldelli de 1968, «El cine político y el mito de las superestructuras» en CAPARRÓS, 1978: 28-31.

42 «Entrevista con Andrés Linares», Cinema 2002, IX/1978: 64-65. ARNAU, 2006: 377. 
el eje común de todos los filmes fue expresar - y subrayar- la presencia pública del partido. El montaje Amnistía y libertad, con material registrado entre diciembre de 1975 y marzo de 1976, es un buen ejemplo. Recogía varios episodios de movilización laboral, universitaria y vecinal, e incorporaba opiniones de dirigentes o militantes, dando forma plástica a la estrategia de ofensiva organizativa. Esa orientación había quedado trazada en la declaración del Comité Ejecutivo de enero, fundamentándose en los objetivos de reforzar la presión frente al Gobierno Arias, apuntalar el entendimiento con la oposición, y configurar «un partido de cientos de miles de militantes, y miles y miles de cuadros», capaz de encuadrar la conciencia ciudadana favorable al cambio $^{43}$. Dicha idea prolongaba una tendencia anterior, interesada por vertebrar al PCE como «organización de masas en la clandestinidad» ${ }^{44}$. Implicaba aglutinar y coordinar un vasto tejido conformado por el movimiento obrero, el vecinal, el estudiantil, el profesional o el cultural, basado en la presión táctica, pero, sobre todo, en «salir a la superficie»" ${ }^{45}$.

Otro film emblemático del CCM fue Hasta siempre en la libertad, con guión de Manuel Vázquez Montalbán y Carlos Álvarez. Era una crónica de urgencia sobre el entierro de los abogados asesinados, el 24 de enero de 1977, por un comando de extrema derecha en un bufete de la calle Atocha de Madrid. El documental encuadraba aquel hecho en coherencia con el discurso del partido en vísperas de la legalización. Su prólogo contraponía la disciplinada movilización del sepelio frente a los residuos «nostálgicos» de la dictadura, interesados en desestabilizar desde «la vía del caos». Recuperaba así el referente antifranquista, actualizándolo como vector de identidad, reconocimiento y legitimación del partido en coherencia con las declaraciones formuladas en aquellas mismas jornadas ${ }^{46}$. Esa fue también la clave dramática utilizada en la ficción posterior 7 días de enero (Juan Antonio Bardem, 1978). Su guión confrontaba una amplia concepción de lo «democrático» — que incluía la lucha pacífica militante y la reconciliación como catarsis social—, frente a lo «reaccionario», es decir, la violencia ultra y la memoria franquista presente en sectores militares, eclesiásticos, empresariales o policiales.

\section{El diseño de una nueva visibilidad mediática}

Desde mediados de 1976 tomó forma la nueva imagen del PCE trazada genéricamente en el Pleno Ampliado del Comité Central celebrado en Roma

\footnotetext{
43 «Editorial», Nuestra Bandera, I/1976: 3-13.

44 MOLINERO E YSÀS, 20 (2008): 23-28.

45 TREGLIA, 2012: 296-297 y 332-336.

46 Cfr. con Santiago Carrillo, «Reconciliación para la democracia», MO, 27/I/1977: 3.
} 
en julio. Aquel fue un acto con importante repercusión mediática. Tuvo lugar semanas después de la designación de Suárez como Jefe de Gobierno. En su declaración final reiteraba la disponibilidad comunista al diálogo desde el esquema conformado por los objetivos de amnistía, proceso constituyente, reconocimiento de las nacionalidades históricas y aplicación de medidas urgentes frente a la crisis económica. Pero el Pleno exhibió además una representación del partido como comunidad vertebrada. Manifestó su «salida a la superficie», definiendo como propuestas inmediatas lograr el pleno reconocimiento legal, regularizar e incrementar sus afiliados y establecer renovadas estructuras orgánicas ${ }^{47}$.

«La batalla de la democracia hay que librarla ante la opinión pública», declaró Santiago Carrillo al hilo de aquel encuentro. Dicho objetivo se tradujo en una campaña que aprovechó el clima de tolerancia gubernamental. Entre el otoño y el invierno de 1976 se sucedieron las aperturas de agrupaciones, las entregas públicas de carnés o los actos con colectivos específicos, como el dedicado a la «liberación de la mujer» ${ }^{48}$. Su pretensión inmediata fue incrementar la afiliación a doscientos o, incluso, trescientos mil militantes ${ }^{49}$. Pero, asimismo, presentaba un claro sentido funcional, orientándose a apuntalar la presencia y operatividad del PCE como interlocutor clave en el proceso de cambio político ${ }^{50}$. Esas pretensiones guiaron otras iniciativas paralelas, como la campaña "pro Mundo Obrero» ${ }^{51}$, o la presentación pública de dirigentes, como la protagonizada por Carrillo en Madrid en el mes de diciembre. Aquel acto obtuvo una gran repercusión mediática y permitió difundir un discurso oficial ajustado a un prisma posibilista, en el que se seguía explicitando la apuesta por una «república democrática», si bien advirtiendo a continuación que la monarquía era «una realidad» ${ }^{52}$.

Tales declaraciones deben enmarcarse en un contexto donde la capacidad de presión de la oposición se estaba viendo superada por la iniciativa del Gobierno Suárez. El 15 de diciembre tuvo lugar el referéndum sobre la Ley para la Reforma Política, que logró un respaldo favorable de más del $90 \%$ de los votos, mientras que la abstención - la opción defendida por la oposición antifranquista - se limitó a un $22 \%$ del censo. A ello se sumó la fallida huelga general del 12 de noviembre convocada desde la Coordinadora de Organiza-

47 De la clandestinidad a la legalidad, AHPCE, Dirigentes, Santiago Carrillo, 6/2.2.1.57, julio de 1976.

48 «Agrupaciones comunistas», $M O, 8 / \mathrm{XI} / 1976: 6-7$. «Un carnet para un Partido de masas», 17/XI/1976: 1. «Hacia la liberación de la mujer», 17/XI/1976: 8.

49 «La reunión de Roma», $M O$, 1/IX/1976: 1. «Conferencia del Partido en Madrid», 2/VI/1976: 7-8.

50 Informe, AHPCE, Dirigentes, Jaime Ballesteros, 2/1.2.2, octubre de 1976.

51 «El Mundo Obrero y las tareas del Partido», MO, 23/IX/1976: 11.

52 «La conferencia de prensa de Santiago Carrillo en Madrid», MO, 20/XII/1976: 6. 
ciones Sindicales (la COS, integrada por Comisiones Obreras, Unión General de Trabajadores o Unión Sindical Obrera), y que fue impulsada, entre otros, por el PCE. Por su parte, el 8 de diciembre tuvo lugar el XXVII Congreso del Partido Socialista Obrero Español (PSOE), en un clima de práctica legalidad y claro respaldo internacional.

Estos factores permiten situar el giro estratégico comunista donde se sintetizó la renuncia y, al tiempo, el refuerzo de planteamientos derivados del Pleno del mes de julio. Los resultados del referéndum forzaron desistir de reivindicaciones como la creación de un gobierno provisional o una futura consulta sobre la forma de régimen. Pero asimismo acabaron despejando una dinámica de encuentro y transacción entre el gobierno y el PCE, un escenario en parte previsto antes del 15 de diciembre. El objetivo último no había cambiado: lograr un partido hegemónico de masas, sólo que ahora debía tenerse en cuenta el horizonte electoral y sus consecuencias en términos de representatividad ${ }^{53}$. Según un análisis interno, sólo la solidez organizativa podía forzar la legalización, y únicamente desde la legalización cabía alcanzar esa supremacía electoral. Para lograrlo era necesario abandonar el esquema de la «ruptura», puesto que era imposible «imponer(lo) en la forma que originariamente nos planteamos». En contraposición debía facilitarse, desde la lógica de la «campaña electoral, las condiciones más favorables para (construir) el partido de masas ${ }^{54}$.

La legalización y las elecciones abrieron un nuevo espacio para las prácticas propagandísticas y para el posicionamiento del PCE en los medios generalistas. Frente a la percepción negativa otorgada a la televisión franquista, durante la primera mitad de 1977 fueron tomando forma una diversidad de apreciaciones, al tiempo que el partido se incorporaba a la agenda cotidiana de la pequeña pantalla. El referéndum de diciembre suscitó la denuncia comunista sobre el abuso político de TVE como herramienta gubernativa ${ }^{55}$. Semanas después, coincidiendo con la convocatoria electoral, se invocó de nuevo el riesgo de interferencia, si bien esta vez considerando que el peligro de que se usase la televisión desde «sectores reaccionarios» para multiplicar el discurso anticomunista ${ }^{56}$. Sin embargo, la legalización permitió un paulatino proceso de normalización en el régimen de visibilidad del PCE en televisión, algo que implicó tanto al discurso informativo formalizado como a otro tipo de narrativas.

La primera vez que pudo verse a Santiago Carrillo en TVE fue en el Telediario del 22 de diciembre de 1976, donde apareció en poder de la policía con

53 Declaración del PCE ante la Reforma Suárez, AHPCE, 57, 15 de septiembre de 1976. Notas manuscritas, Dirigentes, Jaime Ballesteros, 2/1.2.1. 26 de noviembre de 1976.

54 Informe, AHPCE, Documentos, 58/2, s.f. (¿enero-febrero de 1977?).

55 «TVE: Todos somos minusválidos», MO, 29/IX/1976: 10. «Referéndum», 20/XII/1976: 3. Véase también Boletín de la Confederación Sindical de CCOO de RTVE, AHT, 13/XII/1976.

56 PCE informa, AHPCE, Documentos, 284, ¿febrero de 1977 ? 
motivo de su breve detención. Hasta inicios de junio las referencias al partido fueron muy escasas y, con frecuencia, indirectas. Por ejemplo, el programa Informe Semanal abordó la legalización de los sindicatos de clase, el movimiento vecinal o el restablecimiento de relaciones diplomáticas con la URSS, pero no se hizo eco ni del asesinato de los abogados laboralistas ni de la legalización del PCE. Semejante actitud de silencio evidenció el deseo oficial por una gestión informativa cauta en la televisión pública, que evitase azuzar tensiones o rechazos en especial entre ámbitos conservadores.

La campaña electoral comunista se apoyó en las experiencias adquiridas durante la segunda mitad de 1976, en particular en las iniciativas públicas para reforzar la visibilidad del partido y en las acciones pro-abstención frente al referéndum ${ }^{57}$. En marzo de 1977, desde la organización se recomendó manejar «pocas y concisas (...) directrices generales» con «espíritu militante» ${ }^{58}$. La propaganda directa, las iniciativas de proximidad (informaciones puerta a puerta, en barriadas o centros de trabajo), el uso de medios tradicionales (mítines, octavillas y carteles), el tono explicativo y su focalización sectorial, canalizada a través de agrupaciones laborales o colectivos profesionales, conformaron los ejes vertebrales de dicha estrategia ${ }^{59}$. Los problemas abarcaron desde las dificultades de financiación y la carencia de infraestructuras especializadas, hasta la necesidad de contar con encuestas fiables. También se pretendió informar, «de forma políticamente aséptica», a los electores para evitar fraudes ${ }^{60}$. El proyecto electoral se conformó, por tanto, en clave de proselitismo partidario, pero, sobre todo, de didáctica acerca del valor que suponía la recuperación democrática.

Pedagogía y democratización constituyeron asimismo los ejes del programa electoral sobre medios de comunicación. Sus contenidos quedaron explicitados por militantes de la Agrupación de Periodistas de Madrid. En ellos se manejaron reivindicaciones como el pleno reconocimiento de la libertad de expresión, la «reconversión democrática de (...) radiotelevisión, agencias informativas y prensa estatales», o una descentralización que reflejase las «distintas nacionalidades y lenguas del Estado». En marzo, la Agrupación Comu-

57 Base de discusión, AHPCE, Documentos, 283-1, noviembre de 1976.

58 Cuestiones importantes a tener en cuenta por las candidaturas, AHPCE, Documentos, 284, marzo de 1977.

59 Orientaciones a las organizaciones del Partido, AHPCE, Documentos, 283-1, noviembre de 1976 .

${ }^{60}$ Informe sobre algunos problemas electorales y Plan preparatorio de las elecciones, AHPCE, Documentos, 283-1 y 284, abril-mayo de 1977. No hemos localizado información en el AHPCE sobre la financiación de la campaña. Según datos publicados en prensa, su coste ascendió a 141 millones de pesetas, mientras que los ingresos por aportaciones personales o compra de bonos rondaron 15 millones y se suscribieron varios créditos por valor cercano a cien millones. El País, 23/VI/1977: 13. 
nista de Radio y Televisión de Madrid había formulado un corpus de medidas detalladas en forma de «alternativa democrática» para TVE: garantizar su independencia y pluralidad, revisar su programación impulsando la producción propia, fomentar los espacios formativos en aras de la «educación del pueblo»... Todo ello reflejaba el modelo clásico de televisión de servicio público, un enfoque que terminó de concretarse con la reclamación de mantener la exclusividad estatal en la titularidad y gestión del medio, impidiéndose la creación de canales comerciales privados ${ }^{61}$.

La Agrupación de Televisión se organizó como comisión de seguimiento ante posibles irregularidades. Según Mundo Obrero, entre el 18 de abril y el 12 de mayo la información sobre Unión de Centro Democrático ocupó cuatro veces más tiempo que el dedicado al resto de partidos, mientras que el otorgado al PCE se limitó únicamente a cuatro minutos ${ }^{62}$. Finalmente, la primera referencia relevante al proyecto electoral comunista tuvo lugar en el «primetime» del 20 de mayo, al hilo de una intervención de Santiago Carrillo. Junto a la presentación de las líneas básicas del programa, se pretendió neutralizar la desfavorable «imagen que de los comunistas ha creado el franquismo durante los últimos 40 años» ${ }^{63}$. Desde finales de 1976 periódicos conservadores y ultraderechistas habían recuperado el recuerdo de viejos episodios traumáticos, como la vinculación del PCE a la URSS o la participación comunista en acciones represivas durante la guerra ${ }^{64}$. Eran claves de memoria reconocibles por los sectores sociales más sensibles a la cooptación franquista y al etiquetaje de lo «comunista» según el esquema discursivo de la dictadura. El propio Carrillo había aludido, en noviembre de 1975, a esta posible instrumentación ante las clases medias o "sectores atrasados de los trabajadores», temerosos de una nueva guerra civil o una radicalización similar a la que se estaba viviendo en Portugal en esos meses ${ }^{65}$.

Los «spots» electorales - emitidos el 31 de mayo, y el 7 y 13 de junioreiteraron ese mismo tono ${ }^{66}$. Evidenciaron una estrategia generalista encaminada a subrayar los aspectos más moderados del programa del partido, llegando al límite de discutir algunas claves identitarias tradicionales. Por ejem-

${ }^{61}$ Por una alternativa democrática en la información y Una alternativa democrática para la radio y la televisión, AHPCE, Documentos, 284, mayo y marzo de 1977.

62 Aurora Martín, «Muralla china en RTVE o la información secuestrada» y «Juego limpio», $M O, 9$ y 23/V/1977: 15 y 10.

63 Informe politico, AHPCE, Documentos, 284, 15 de abril de 1977.

64 «Carrillo en TVE. Máscaras políticas», $A B C, 24 / \mathrm{V} / 1977: 2$. Ángel Gibello, «Carrillo, genocida de Paracuellos», El Alcázar, 5/I/1977: 3. José Manuel Martínez Bande, «Verdadera historia de la sinuosa infiltración comunista en España», $A B C$, 12/VI/1977: 56-63.

65 «Franco desaparecido», Nuestra Bandera, 11/1975: 7. Como comparación entre las estrategias comunistas española y portuguesa, CARDEIRA, 242 (Madrid, 2012): 669-698.

${ }^{66}$ MARTÍN JIMÉNEZ, 2011: 597-608. 
plo, en el primero de aquellos programas, Ramón Tamames afirmó que los comunistas «no estamos en contra de la propiedad privada», mientras que el segundo presentó una extensa galería de rostros populares o personas anónimas que explicitaron su simpatía al partido no como organización de pasado, sino como proyecto de futuro.

El «spot» electoral del 13 de junio contó, de nuevo, con Santiago Carrillo. Este espacio cerraba la campaña en televisión, incluyéndose en un programa especial con la propaganda de partidos o coaliciones que presentaban candidaturas en al menos veinticinco circunscripciones. En él se enfatizaron tres ideas esenciales. Carrillo insistió en el papel jugado en el proceso hacia la democracia, aunque obvió el período de oposición al franquismo, y recalcó, por contra, el objetivo de coadyuvar en la construcción de la legitimidad democrática. En segundo término, destacó la independencia del PCE frente a intereses extranjeros. Por último, subrayó el compromiso con la «reconciliación nacional» como activo patrimonial del partido, lo cual debía traducirse en superar la guerra, «un recuerdo histórico» que no podía dictar ni el ritmo del presente ni del futuro ${ }^{67}$. En este sentido, por tanto, los referentes de memoria actuaron como ejes de aquella intervención, si bien no tanto desde un plano de «amnesia» como de olvido selectivo instrumental.

Estas muestras paulatinas de presencia comunista en televisión deben complementarse con otras narrativas coetáneas que manejaron valores simbólicos propios de un universo «de izquierdas». Fueron ejercicios configurados desde diferentes claves de género y que provocaron algunas reacciones o polémicas ocasionales, al tiempo que discutieron (o transgredieron) los límites del discurso oficial existente en el medio. Entre 1973 y 1975 pueden detectarse producciones formuladas mediante recursos metafóricos o paródicos. Fue el caso de Juan Soldado (1973), una fábula con guión de Lola Salvador, y realización e interpretación de Fernando Fernán Gómez, que satirizaba al Ejército y la iconografía religiosa. En otros espacios dirigidos al público infantil se ridiculizaron, desde una óptica aparentemente ingenua, otras instituciones o normativas. Así ocurrió en Cuentopos (1974-1975), con guión de María Elena Walsh y realización de Miguel Picazo, donde actuaron algunos militantes del PCE, como Tina Sainz, Juan Diego o Rosa León. Ya en 1977, otros formatos amplificaron este imaginario crítico. Cabe citar al respecto El hombre de los santos, una serie de ficción con realización de Miguel Picazo sobre un texto de Jesús Fernández Santos; o el episodio «La gran batalla de Andalucía» de Curro Jiménez, que contó con dirección de Antonio Drove y guión de Antonio Larreta ${ }^{68}$.

También puede mencionarse el polémico musical protagonizado por el cantautor Luis Pastor, grabado en el madrileño barrio de Vallecas (Yo canto,

67 Cfr. con MOLINERO, 66 (Madrid, 2007): 201-225.

68 Algunos de estos ejemplos han sido analizados en PALACIO, 2012: 63-65 y 181-184. 
con realización de Alfonso Ungría). Por el contrario, hubo que esperar a inicios de diciembre para que se levantara el veto y pudiese programarse un musical de los cantantes comunistas Víctor Manuel y Ana Belén, filmado por Pilar Miró meses antes. Por su parte, el espacio Encuentros con las Letras dedicó entregas a temas como la cultura durante la II República y el exilio, o a intelectuales como Fernando Arrabal y Jorge Semprún. Por su parte, el 3 de julio se emitió en el espacio de entrevistas $A$ fondo una charla con Rafael Alberti, recién llegado del exilio y elegido diputado.

\section{CONCLUSIONES: SOCIALIZACIÓN, MEDIOS Y DISCURSO COMUNISTA}

La retrospectiva general que hemos planteado sobre las estrategias mediáticas vinculadas al PCE, así como sobre las prácticas de representación de lo comunista durante el tardofranquismo y el inicio de la transición, denotan una doble dimensión interpretativa que cabe abordar en términos de proyección y límite. No puede concebirse el alcance político y social del PCE, o su protagonismo durante la recta final de la dictadura, sin atender a su discurso mediático, y, sin duda, éste confluyó en un marco más general —el desmontaje simbólico del franquismo en el espacio público-, que tomó forma durante la transición. Pero, por otra parte, los límites de ese discurso también resultan claros. La proyección pública del PCE se acompasó obviamente a los pasos coyunturales desarrollados por esta organización entre noviembre de 1975 y junio de 1977, o, lo que es lo mismo, al tránsito desde un proyecto y unas expectativas de ruptura a otro de corte reformista.

En este sentido, el discurso mediático y, con posterioridad, electoral del PCE puede correlacionarse con una panorámica más amplia integrada por el conjunto del ecosistema mediático. Una tendencia evidente a mediados de los años setenta fue la creciente diversificación de opiniones en la prensa o en el cine, lo cual facilitó la socialización de una legitimidad posfranquista de amplia base ${ }^{69}$. Sin embargo, respecto a la oferta cinematográfica, la superación de los corsés impuestos por la dictadura o la propia denuncia directa del franquismo no conllevaron, ni mucho menos, a la centralidad de un «cine radical rupturista». A pesar de la intensa politización del relato fílmico, las opciones más rupturistas fueron periféricas y coyunturales, y quedaron superadas por la hegemonía de un cine posfranquista globalmente orientado a reflejar y amplificar objetivos democráticos reformistas. Esa misma lógica es aplicable a la trayectoria de la propaganda del PCE, así como a las pautas de presencia pública del partido y a su normalización en los medios generalistas. En pala-

\footnotetext{
${ }^{69}$ QUIROSA-CHEYROUZE, NAVARRO PÉREZ y GARCÍA RUIZ, 2007.
} 
bras de Andrés Linares, promotor del CCM, a inicios de 1977 se tuvo plena conciencia ya de que «habíamos perdido virtualidad» ${ }^{70}$. Esa situación de agotamiento puede relacionarse, por otro lado, con la transición vivida en TVE, y con su conversión en un ámbito abierto a representaciones más plurales.

Durante el tardofranquismo y el inicio de la transición tuvo lugar una relevante actividad pública del PCE, que permitió que ganase presencia y cotidianeidad en la esfera pública. Sin embargo, esa visibilidad no impidió el fracaso del objetivo de trasladar al entorno democrático el protagonismo disfrutado durante el ocaso de la dictadura, logrando un alcance social y parlamentario equiparable al del PCI. La evidencia de dicho fracaso se constató con los malos resultados del 15 de junio, que conllevaron la pérdida de la hegemonía en la izquierda frente al PSOE.

Algunos dirigentes valoraron a posteriori las causas de este fracaso. Para Víctor Díaz-Cardiel, responsable del partido en Madrid, 1976 constituyó el momento clave para la sedimentación orgánica del PCE, al «salir a la superficie» y encabezar la intensa movilización que salpicó los meses iniciales de aquel año. La aceptación de la bandera franquista y la monarquía supusieron, en cambio, los factores que habrían precipitado el desdibujamiento comunitario, y con él, ese déficit de representatividad ${ }^{71}$. Santiago Carrillo defendió, por contra, la coherencia de la moderación y, sobre todo, su valor para desactivar el rechazo o el miedo al partido presente en distintos sectores sociales y políticos. Según su lectura, los malos resultados en los comicios de 1977 habría que buscarlos en posibles errores de concepción y desarrollo de la campaña electoral ${ }^{72}$.

Cabe preguntarse hasta qué punto las expectativas de socialización conllevaron el afianzamiento inevitable del moderantismo comunista. O bien lo contrario: si el énfasis en el objetivo parlamentario - siquiera como primera fase hacia una «democracia social y económica»y, desde ahí, a un «socialismo en libertad», según el enfoque terminológico de la época- acabó incidiendo en la descomposición del PCE. En relación con este extremo deben señalarse algunas particularidades de su carácter como organización de masas. El partido arribó al ecuador de los años setenta como paradigma en la lucha antifranquista. El interés por prolongar ese protagonismo fue una constante en su estrategia durante el tramo final de clandestinidad, en el período de permisividad relativa previo a la legalización o durante la campaña electoral. De hecho, desde finales de los años sesenta el análisis oficial había ligado ese objetivo de robustecer la presencia pública del PCE con la consecución de un tejido organizativo más activo y fluido, capaz de encuadrar sectores sociales diversos, encabezar distintos frentes de movilización (sindical, profesio-

70 TRENZADO, 1999: 89, 280 y 328-330.

71 DÍAZ-CARDIEL, 2007.

72 CARRILLO, 1993: 622, 626, 659 y 668. 
nal, cultural, estudiantil, vecinal...), y forzar el cambio político, ya tildado literalmente como de «transición hacia la democracia» ${ }^{73}$. A su vez, esa experiencia social y organizativa, configurada en el marco de la oposición contra la dictadura, sirvió como constante expresión de legitimación para la cultura militante, antes y después de la legalización ${ }^{74}$.

Pero es en esas mismas coordenadas donde deben situarse los factores que problematizaron la identidad comunista. La impronta antifranquista otorgó al PCE una nítida consistencia en términos de percepción y reconocimiento. Fue eje de su discurso y clave de su acción colectiva, además de vínculo entre las bases y marca de distinción ante la sociedad española ${ }^{75}$. Pero su formulación no impidió las líneas de fractura. En este sentido tuvieron lugar, por ejemplo, llamativas disidencias ideológicas o personales en la elite dirigente, como la encabezada por Líster (1968-1973). A su vez, buena parte de la «izquierda a la izquierda del PCE» durante la transición provenía de distintas rupturas en el partido, y siempre coincidió, a pesar de su fragmentación, en rechazar la estrategia de «reconciliación nacional» formulada en $1956^{76}$.

A estas cuestiones cabe sumar las contradicciones derivadas del crecimiento de la organización. El colectivo comunista integró militantes del interior y de la emigración con diferentes experiencias vitales, junto a trabajadores provenientes de matrices diversas. El PCE logró además, en el ocaso de la dictadura, un fuerte arraigo entre intelectuales y profesionales liberales. Pero esa misma pluralidad acabó actuando como factor de dispersión según se diluía el elemento aglutinador antifranquista. Finalmente, debe añadirse el impacto de dinámicas como la crisis económica, las mutaciones en las relaciones laborales o familiares, la eclosión de nuevas subculturas o la extensión de hábitos ligados al consumo de masas ${ }^{77}$. Por otra parte, la paulatina emergencia del PCE, en forma de «salida a la superficie», trajo consigo nuevas dificultades y tensiones de orden financiero y organizativo ${ }^{78}$. Todo ello acabó conformando, entre 1975 y 1977, un complejo contexto de circunstancias que afectó a su articulación identitaria, a sus modelos discursivos, a las tácticas de movilización o a la presencia comunista ante otras fuerzas políticas.

En este escenario, la reflexión sobre cómo usar y aprovechar los medios de comunicación ocupó una posición secundaria — cuándo no fue directamente soslayada - en la publicística política generada por el aparato oficial. Dicha

73 Declaración del Comité Ejecutivo de abril de 1967. Por un Partido Comunista de masas para acelerar la transición hacia la democracia, AHPCE, Documentos, 48, 4.

74 Cfr. con Informe del Partido C. de Aluche, FFLC, 001704-008, 1977.

75 MOLINERO e YSÀS, 20 (2008): 21-42.

76 LAIZ, 1995: 30.

77 DOMÉNECH, 2009: 133-138. ERICE, 2009: 176-181.

78 Comité Provincial de Sevilla, AHPCE, Documentos, 57, diciembre de 1976. 
cuestión puede apreciarse, por ejemplo, en las escasas referencias dedicadas a esta cuestión en el Manifiesto-Programa de 1975, el documento estratégico más relevante de aquel período ${ }^{79}$.

Esta carencia plantea una interesante paradoja. La iniciativa propagandística siempre constituyó una esfera crucial para la praxis comunista, y siguió jugando ese rol en el decenio de los setenta. Desde una óptica clásica de «agit-prop», resultaba inconcebible concebir y planificar cualquier trabajo de masas sin tener en cuenta esa dimensión. La «galaxia PCE», el tejido conformado por medios y ámbitos de sociabilidad vinculados al partido, suministró en los años treinta un arsenal de discursos, argumentos, retóricas o expresiones plásticas, centrales para sustanciar su sistema de ideas y valores ${ }^{80}$. Como se ha apuntado en este trabajo, durante la dictadura la maquinaria mediática continuó articulando pautas de afirmación e interacción, y actuó como acicate de movilización y «cemento» para la organización ${ }^{81}$. Pero la propaganda encarnó, además, un intenso potencial como mecanismo inclusivo frente al riesgo de disgregación que podían correr bases y cuadros. A su vez, según un informe anónimo de abril de 1973, el propagandista no sólo debía caracterizarse por un «alto nivel de conciencia política» o «buen conocimiento de los materiales del (partido)». También por saber aparentar una «vida profesional y familiar normal (...), con toda la seriedad» ${ }^{82}$.

Entre los años sesenta y setenta se produjo, además, un rebrote de reflexiones teóricas sobre el poder de los medios. En ese contexto debe situarse, por ejemplo, la popularización de la obra de Mc Luhan. Sus trabajos, empapados de una concepción determinista sobre la incidencia de los medios en la cultura y la política, inspiraron interpretaciones acerca del carisma televisivo de figuras como Adolfo Suárez ${ }^{83}$. Paralelamente - al hilo de una actualidad marcada por las campañas electorales de 1977 y 1978_, la Revista Española de Investigaciones Sociológicas publicó un destacado trabajo de Elizabeth Noelle Neumann. Esta socióloga había formulado poco antes su conocida tesis sobre la «espiral de silencio», donde remarcaba la capacidad de generación de climas de opinión política desde el entramado mediático ${ }^{84}$.

La idea de «impacto (...) inmenso» del cine o la televisión se planteó en ámbitos intelectuales comunistas, contrastando con esa escasez relativa de

79 Manifiesto-Programa, AHPCE, Documentos, 56, 9. Su debate en AHPCE, DVD108/CM-37.

80 La noción «galaxia PCE», en HERNÁNDEZ SÁNCHEZ, 2010: 293-315.

81 Véase, por ejemplo, «Comandos y lucha de masas», Hora de Madrid, II/1969, p. 1, cit. en TREGLIA, 2012: 253.

${ }^{82}$ La importancia e influencia de los medios de comunicación, AHPCE, Nacionalidades y Regiones (Canarias), 259, abril de 1973.

83 Cfr. con El País, 2 y 4/I/1981.

84 NOELLE NEUMANN, 4 (1978): 67-101, y 24/2 (1974): 43-51. 
reflexiones sobre los medios en su discurso político ${ }^{85}$. No olvidemos tampoco que fue en el ecuador de los setenta cuándo se hizo más patente la influencia de la tríada conformada por el estructuralismo marxista, la semiótica y el psicoanálisis. Sus enfoques sobre las funciones socioculturales de la comunicación o las industrias culturales tomaron forma a través de la divulgación académica, las publicaciones especializadas (La Mirada, Contracampo, Mensaje y Medios o Comunicación XXI) o la crítica cinematográfica (colectivos «Marta Hernández» $\mathrm{y}\langle\mathrm{F}$. Creixells»). No obstante, fueron puntuales las reflexiones que trascendieron esos círculos y se proyectaron sobre la prensa oficial de partidos de izquierda. Una posible excepción la encontramos en «Estructura de la propiedad de los medios de comunicación de España», un monográfico de El Cárabo, la revista de análisis social dirigida por Joaquín Estefanía vinculada a la maoísta Organización Revolucionaria de Trabajadores (ORT). Dicha entrega, publicada a inicios de 1977, diseccionaba el mercado español de la comunicación, aunque atendiendo en particular a la prensa escrita ${ }^{86}$.

Según se ha intentado ejemplificar en este trabajo, las modalidades de presencia pública comunista fueron relativamente heterogéneas en el tardofranquismo y la transición. Algunos estudios han resaltado que, durante la dictadura, la interacción entre el partido y los sectores sociales más o menos proclives a su discurso resultó irregular, fundamentándose en una articulación directa establecida por las condiciones de conflicto y clandestinidad. En cambio, desde 1976 esa lógica se invirtió. El PCE se situó en unas coordenadas institucionales que facilitaron el desmantelamiento del modelo relacional propio de la ilegalidad. Fue tomando forma, así, una imagen pública normalizada, si bien ésta fue fruto, sobre todo, de representaciones mediadas indirectas, externas a la propia organización y, en ocasiones, de tono hostil ${ }^{87}$.

El PCE fue legalizado el 9 de abril de 1977, aunque es obvio que sus dinámicas de socialización no partían de cero. Durante el tramo final de la dictadura tuvo lugar una progresiva multiplicación de «espacios de libertad»a pesar de la censura y la restricción ideológica, en terrenos como la creación teatral, musical, literaria, cinematográfica o periodística. En términos genéricos, la estrategia formulada por la dirección comunista hacia las «fuerzas de la cultura» (estudiantes, intelectuales o profesionales), especialmente desde el VIII Congreso (1972), fue que se implicasen y potenciasen esos espacios como coadyuvantes para la descomposición del régimen. Al inicio de la transición se intentó vertebrar un tejido orgánico que integrase estos sectores. Sin

\footnotetext{
${ }^{85}$ Primera conferencia.., AHPCE, p. 13.

${ }^{86}$ El Cárabo, III/IV1977.

87 ANDRADE, 2012: 313.
} 
embargo, en la práctica, tan sólo debe hablarse de iniciativas puntuales, sin que se lograse sedimentar una estructura sólida en ese sentido ${ }^{88}$.

La historiografía ha resaltado la implicación de los medios de comunicación en la cristalización de una cultura política ciudadana fundamentada en nociones como participación, estabilización o consenso, unos principios explícitamente defendidos por el $\mathrm{PCE}^{89}$. Esa dinámica coincidió, desde 1979, con el inicio de la crisis y descomposición comunista y con la progresiva desafección de buena parte de esa base intelectual y profesional. Ese fue el momento en que se evidenció la definitiva incapacidad del PCE para disponer de instrumentos mediáticos propios eficaces, tanto desde el plano de su viabilidad económica como de su capacidad socializadora a gran escala. Ese fenómeno coincidió con la dispar evolución comercial vivida por publicaciones como La Calle, Materiales/Mientras Tanto, Taula de Canvi, Ozono, Teoría y Práctica o El Viejo Topo en su primera etapa, ubicadas en lo que podría denominarse el espacio cultural alternativo a los medios generalistas. Respecto al PCE, la crisis de Mundo Obrero diario puso de manifiesto el fracaso de un proyecto de prensa de partido competitiva con aspiraciones generalistas. La idea de publicar diariamente Mundo Obrero se venía manejando desde inicios de los setenta y se hizo realidad en noviembre de 1978, tras una emisión de bonos de ayuda por valor de 200 millones de pesetas. Sin embargo, su tirada, volumen de suscripciones y facturación publicitaria se mantuvieron muy lejos de las expectativas iniciales: frente a los 100.000 ejemplares previstos, sólo se logró editar una media de 30.000 , que cayó a apenas 10.000 en 1980. Finalmente el periódico acabó despidiendo a un centenar de trabajadores y cerró provisionalmente en junio de aquel año ${ }^{90}$.

La crisis de Mundo Obrero tuvo lugar en paralelo a otros cambios en el escenario mediático próximo al partido. La normalización mediática del PCE coincidió con las primeras expresiones del desencanto y con la difusión de un primer imaginario desmitificador de la transición. Cabe mencionar, al respecto, el documental Después de... (Cecilia y Juan José Bartolomé, realizado entre 1979 y 1981, pero estrenado en 1983), o desilusionantes retratos televisivos, como el dedicado a Valentín González, «el Campesino», en el programa de TVE Rasgos (1982). Fueron narraciones cercanas en el tiempo a los relatos epigonales del cine militante. Dos de sus últimas muestras fueron Una fiesta por la democracia (o el oro del PCE) (1978) y Dolores (1980). La primera era fruto de una idea de Juan Antonio Bardem que contó con realización

88 «PCE, arte y cultura. Libertad de creación», MO, 16/II/1977: 11.

89 PINILLA, 2008. QUIROSA-CHEYROUZE, 2009.

90 José Luis Gutiérrez, «El desastre de Mundo Obrero», Diario 16, 24/IX/1980: 5. Joaquín Prades, «Dura autocrítica del PCE sobre la actuación en el conflicto de Mundo Obrero», El País, 10/XII/1980: 23. 
de Andrés Linares. Recogía el mitin del PCE en Torrelodones, en el cierre de la campaña electoral de 1977, mientras que Dolores — con guión y realización de Linares y José Luis García Sánchez- actualizaba la figura y, sobre todo, el mito simbólico de «Pasionaria», si bien ya en vísperas de un nuevo período: el de la estabilización del sistema surgido entre 1975 y $1977^{91}$.

\section{BIBLIOGRAFÍA}

Andrade, Juan Antonio, El PCE y el PSOE en (la) transición. La evolución ideológica de la izquierda durante el proceso de cambio político, Madrid, Siglo XXI, 2012.

Arnau, Roberto, La guerrilla de celuloide: resistencia estética y militancia política en el cine español (1967-1981), Berlín, Verlag, 2006.

Barranqueiro, Encarnación, «Ángeles o demonios. Representaciones, discursos y militancia de las mujeres comunistas», Arenal. Revista de Historia de las Mujeres, 19/1 (Granada, 2012), 103-140.

Bueno, Manuel y Sergio Gálvez, «Apuntes en torno a la bibliografía sobre la historia del PCE», Papeles de la FIM, 24 (Madrid, 2005), 335-345.

Bueno, Manuel y otros (coords.), Historia del PCE. I Congreso, 1920-1977, Madrid, FIM, 2007.

Bueno, Manuel y Sergio Gálvez (eds.), Nosotros los comunistas. Memoria, identidad e historia social, Madrid, FIM, 2009.

Camí-Vela, María, «Entre la esperanza y el desencanto. El cine militante de Helena Lumbreras», en Aranda, Daniel y otros (eds.), Puntos de vista. Una mirada poliédrica a la historia del cine, Barcelona, UOC, 2009; 207-223.

Caparrós, José María, El cine político visto después del franquismo, Barcelona, Dopesa, 1978.

Cardeira Varela, Raquel, «Cunhal não foi Carrillo? Estratégia e Táctica do Partido Comunista Português durante a Crise Revolucionária de 1975», Hispania, 242 (Madrid, 2012): 669-698.

Carrillo, Santiago, Memorias, Barcelona, Planeta, 1993.

Cerdán, Josetxo, «Haciendo estudios culturales. Del NCE a la televisión española a través de Cuadernos para el Diálogo (1963-1978)», en El cine español durante la Transición democrática (1974-1983). IX Congreso de la Asociación de Historiadores del Cine, Cuadernos de la Academia, 13-14 (Madrid, 2005); 219-233.

Cerón, Juan Francisco, «Militancia y posibilismo», en Castro de Paz, José Luis y Pérez Perucha, Julio (coords.), El cine a codazos: Juan Antonio Bardem, Ourense, Festival Internacional de Cine Independiente, 2004; 29-37.

Cruz, Rafael, Pasionaria. Dolores Ibárruri, Historia y Símbolo, Madrid, Biblioteca Nueva, 1999.

91 Sobre el mito de Dolores, CRUZ, 1999: 11-27 y 231-238. 
Cruz, Rafael, «Como Cristo sobre las aguas. La cultura política bolchevique en España», en Morales Moya, Antonio (coord.), Ideologías y movimientos politicos, Madrid, Nuevo Milenio, 2001; 187-201.

Dawisha, Karen, «Communism as a Lived System of Ideas in Contemporary Russia», East European Politics and Societies 19/3 (Londres, 2005), 463-493.

Díaz-Cardiel, Víctor: «Aportación-Testimonio», Comunicaciones del II Congreso de Historia del PCE. De la resistencia antifranquista a la creación de Izquierda Unida. Un enfoque social, Madrid, FIM, 2007; 25.

Díaz Puertas, Emeterio, Historia del movimiento obrero en la industria española del cine, 1931-1999, Valencia, Ediciones de la Filmoteca-IVC Ricardo Muñoz Suay, 2001.

Doménech, Xavier, «Cenizas que ardían todavía: la identidad comunista en el tardofranquismo y la transición», en Bueno, Manuel y Sergio Gálvez (eds.), Nosotros los comunistas. Memoria, identidad e historia social, Madrid, FIM, 2009; 93-137.

Dowling, Andrew, «The Leading Role of the Party: Catalan Communism and the Franco Regime, 1939-1975», European History Quarterly, 43, 3 (Londres, 2013), 489-507.

Erice, Francisco, «Un balance sobre los estudios recientes del comunismo en España), Ayer, 48 (Madrid, 2002): 315-330.

Erice, Francisco, «El orgullo de ser comunistas. Imagen, autopercepción, memoria e identidad colectiva de los comunistas españoles», en Bueno, Manuel y Gálvez, Sergio (eds.), Nosotros los comunistas. Memoria, identidad e historia social, Madrid, FIM, 2009; 139-183.

Fuertes, Carlos, «La representación de las actitudes políticas de los españoles en la prensa extranjera (1960-1975): un modelo de análisis», en Del Arco, Miguel Ángel y otros (eds.), No solo miedo. Actitudes políticas y opinión popular bajo la dictadura franquista (1936-1975), Granada, Comares, 2013; 111-126.

Garrido, Magdalena y González, Carmen, «El Puente a la Transición y su Resultado Final. Actitudes del PCE y de la militancia comunista en la Transición Española», Revista de Historia Actual, 6 (Cádiz, 2008), 71-87.

Ginard, David, «La investigación histórica sobre el PCE: desde sus inicios a la normalización historiográfica», en Bueno, Manuel y otros (coords.), Historia del PCE. I Congreso, 1920-1977, 1, Madrid, FIM, 2007; 19-47.

Gutiérrez Lozano, Juan Francisco, La televisión en el recuerdo. La recepción de un mundo en blanco y negro en Andalucía, Málaga, Universidad-RTVA, 2006.

Hall, Stuart, "Culture, the Media and the Ideological Effect», en Curran, James y otros (eds.), Mass Communication and Society, Londres, Edward Arnold, 1977; 315-348.

Hernández Corchete, Sira, «La mirada documental de la Guerra Civil en el tardofranquismo y la Transición», en Hernández Corchete, Sira (ed.), La Guerra Civil televisada. La representación de la contienda en la ficción y el documental espanoles, Salamanca, Comunicación Social, 2012; 23-52.

Hernández Sánchez, Fernando, Guerra o Revolución. El Partido Comunista de España en la Guerra Civil, Barcelona, Crítica, 2010. 
Laiz, Consuelo, La lucha final. Los partidos de la izquierda radical durante la transición española, Madrid, Los Libros de la Catarata, 1995.

López Hernández, María Teresa, «Las relaciones de género en la prensa comunista: del franquismo a la democracia», Studia Historica. Historia Contemporánea, 25 (Salamanca, 2007), 381-396.

Martín Jiménez, Virginia, «De la clandestinidad a los spots. El discurso televisivo del PCE durante la Transición», en Rafael Quiroga-Cheyrouze y otros (eds.), Las organizaciones politicas, Almería, Universidad, 2011; 597-608.

Molinero, Carme, «La política de reconciliación nacional. Su contenido durante el franquismo, su lectura en la Transición», Ayer, 66 (Madrid, 2007), 201-225.

Molinero, Carme e Ysás, Pere, «La izquierda en los años setenta», Historia y Política, 20 (Madrid, 2008), 21-42.

Molinero, Carme e Ysàs, Pere, Els anys del PSUC. El partit de l'antifranquisme (1956-1981), Barcelona, L'Avenç, 2010.

Nistal, Fernando, «La legalización del PCE a través de sus medios», en Bueno, Manuel (coord.), Comunicaciones del II Congreso de Historia del PCE. De la resistencia antifranquista a la creación de Izquierda Unida. Un enfoque social, Madrid, FIM, 2007; 19.

Noelle Neumann, Elizabeth, «The Spiral of Silence. A Theory of Public Opinion», Journal of Communication, 24/2 (Nueva York, 1974), 43-51.

Noelle Neumann, Elizabeth, «El doble clima de opinión: la influencia de la televisión en una campaña electoral», Revista Española de Investigaciones Sociológicas, 4 (Madrid, 1978), 67-101.

Pala, Giaime, «El frente cultural. Sobre la trayectoria de la revista Nous Horitzons (1960-1976)», Spagna Contemporanea, 38 (Turín, 2010), 85-108.

Palacio, Manuel, Historia de la televisión en España, Barcelona, Gedisa, 2005.

Palacio, Manuel, La televisión durante la Transición española, Madrid, Cátedra, 2012.

Pinilla, Ángel, La transición de papel. El atentado contra Carrero, la legalización del PCE y el 23-F, Madrid, Biblioteca Nueva, 2008.

Prieto, Xosé, «Pensar el cine desde el Archivo del PCE», XII Congreso de la Asociación de Historiadores de la Comunicación. Comunicaciones, Barcelona, Universitat Pompeu Fabra, 2012. Disponible en: http://ashiscom.org/12congreso/ es/program.php

Prieto Souto, Xose, «Reflexiones sobre los medios audiovisuales en las publicaciones clandestinas del PCE y de las comisiones de trabajadores y trabajadoras del cine y la televisión», Studies in Spanish and Latin American Cinemas, 10/2, (Londres, 2013), 181-195.

Quirosa-Cheyrouze, Rafael, Navarro Pérez, Luis Carlos y García Ruiz, Carmen (coords.), El papel de los medios de comunicación. Tercer Congreso Internacional Historia de la Transición en España, Universidad de Almería, 2007.

Quirosa-Cheyrouze, Rafael, (ed.), Prensa y democracia. Los medios de comunicación en la Transición, Madrid, Biblioteca Nueva, 2009. 
Rodríguez Méndez, José María, Los Teleadictos, Barcelona, Laia, 1971.

Rodríguez Méndez, José María, Carta abierta a Televisión Española, Madrid, Ediciones 99, 1973.

Rueda, José Carlos y Chicharro, Ma del Mar, La televisión en España (1956-2006). Política, consumo y cultura televisiva, Madrid, Fragua, 2006.

Salvador, Alicia, De iBienvenido Mr. Marshall! A Viridiana. Historia de UNINCI: Una productora cinematográfica española bajo el franquismo, Madrid, Egeda, 2006.

Tileagã, Cristian, «Communism in Retrospect: The Rhetoric of Historical Representation and Writing the Collective Memory of Recent Past», Memory Studies, 0/0 (Londres, 2012), 1-17.

Treglia, Emmanuele, Fuera de las catacumbas. La política del PCE y el movimiento obrero, Madrid, Envida, 2012.

Trenzado, Manuel, Cultura de masas y cambio político: el cine español de la transición, Madrid, CIS, 1999.

Uría, Jorge, «Asturias, 1920-1937. El espacio cultural comunista y la cultura de la izquierda: historia de un diálogo entre dos décadas», en Erice, Francisco (coord.), Los comunistas en Asturias (1920-1982), Oviedo, Trea, 1996; 249-311.

Vázquez Montalbán, Manuel, El libro gris de Televisión Española, Madrid, Ediciones 99, 1973.

Zaragoza, Luis, Radio Pirenaica. La voz de la esperanza antifranquista, Madrid, Marcial Pons, 2008.

Recibido: $24 / 01 / 2013$

Aceptado: 07/11/2013

Hispania, 2015, vol. LXXV, nº. 251, sept.-diciembre, págs. 833-862, ISSN: 0018-2141, e-ISSN: 1988-8368, doi: 10.3989/hispania.2015.026 